\title{
From the Maintenance Management until the Physical Asset Management - A Disruptive Paradigm
}

\author{
José Torres Farinha* \\ CEMMPRE, Coimbra, PORTUGAL, ISEC/IPC, Coimbra, Portugal
}

*Corresponding author: José Torres Farinha, CEMMPRE, Coimbra, PORTUGAL, ISEC/IPC, Coimbra, Portugal.

Received Date: July 29, 2020

Published Date: August 18, 2020

\begin{abstract}
This short paper proposes talks about the paradigm changing from the Maintenance Management until the Physical Life Cycle Cost. The maintenance activity has been done over equipment that are acquired by someone, usually without any strategic criterion. However, it is of common sense if we purchase a physical asset with an adequate reliability its Life Cycle will give a good return. In fact, during decades, a model for the Life Cycle of Physical Assets includes the maintenance policy, as has direct implications on the equipment's ROI (return on investment) and Life Cycle Cost (LCC). It is obvious that an adequate purchase, having a strategic plan for each physical asset and for the global physical assets, permits to evaluate, based on a structured and mathematical way, how to maximize the physical assets performance. It is based on these considerations that this short paper discusses a novel model called a life cycle investment (LCI) model instead of the traditional life cycle cost (LCC). The paper proposes a new methodology based on the modified economic life cycle and lifespan methods by including the maintenance policy using key performance indicators of reliability, notably availability, based on the mean time between failures (MTBF) and the mean time to repair (MTTR) parameters.
\end{abstract}

Keywords: Physical Assets; Life Cycle Cost; LCC; Life Cycle Investment; ROI

\section{Life Cycle of Physical Assets and Maintenance} Policies - A Review

Physical asset management is attracting increasing attention, especially after the publication of ISO 5500X standards (ISO 55000, ISO 55001, ISO 55002) and PAS 55. According to ISO 55000, the asset life is the period from "asset creation to asset end-of-life," and the life cycle corresponds to "the stages involved in the management of an asset". Woodward [1] says that "the life cycle cost of an item is the sum of all funds expended in support of the item from its conception and fabrication through its operation to the end of its useful life". According to Goh and Sun [2], "the history of the application of Life Cycle Costing (LCC) began in the UK in the late 1950's." As Lindholm \& Suomala [3] say, "Life Cycle Costing (LCC) is a way of thinking where attention is paid to the total costs that occur during a product's entire life cycle". The authors say that "in addition to the estimation of future costs, an essential feature of
LCC is cost monitoring during a product's life cycle," and "the sum of life cycle costs of many products often substantially exceeds the initial purchase price". Estevan and Schaefer [4] argue, "Life cycle costing is a powerful technique that supports the analytical processes by which managers can make the most cost-effective decisions on options presented to them at differing life cycle stages and at different levels of the life cycle cost estimate". It must be emphasized that United States Department of Energy (USDE) looks at equipment as a final product to be consumed, like any other product. Schuh et al. [5] relate the life cycle to products, saying that "relevant information which can be used to assess the subsequent maintenance costs are requirements for product life cycle, e.g. service costs according to Total Cost of Ownership (TCO) as well as serviceability and maintainability of the product." According to Kianian et al. [6], "Life Cycle Costing (LCC) was initially used by US 
defense department to seek optimal costs for acquiring, owing and operating an equipment during its useful life (also including any disposal costs)". The same authors emphasize that "these cost calculation methods usually do not include the three performance parameters (quality, productivity and availability) of the Overall Equipment Efficiency (OEE) measure, or lost profit, although Life Cycle Profit (LCP) were introduced already 1983 in literature". Spickova \& Myskova [7] say that, "The main goal of the Life Cycle Costing approach is to optimize life cycle costs of the assets or investment project without loss their performance", and the main costs of LCC are the following: investment (acquisition) costs; operation costs; maintenance costs; renewal costs; disposal (retirement) costs. In an interesting paper, Bengtsson \& Kurdve [8] present an LCC or TCO analysis of machining equipment in a Swedish company and discuss life cycle profit (LCP). Farinha [9] presents a global view of the life cycle of physical assets, including some tools to manage their entire life cycle, integrating the ISO $5500 \mathrm{X}$, as well as the relations between maintenance policies and the LCC. According to Ljiljanaet al. [10] "Asset Management is a relatively new discipline that provides methods and tools for effective management of Physical Assets to maximize their utilization during entire Life Cycle..., we recognize that asset governance is a key point for leading role in the development and implement asset management in the company and it is evidence in PAS 55 and the ISO 55000 standards. Katicic, Lisjak \& Dulcic [13] say that physical asset management evolved from maintenance management to provide a holistic view for the management of the life of physical assets. The relevance of evaluating the life cycle of physical assets is summed up by Eicher [12] in the following way: "Investing in hospital infrastructure is not just a financing activity. It is important to consider the whole life cycle of an asset.... Banyani \& Then [14] present a study showing how physical facilities management can be perceived at different levels of maturity based on personal judgement. They note the lack of a tool to assess maturity levels and propose an integrated feeder factors framework as a yardstick. In the same vein, Volker, Telli \& Ligtvoet [15] mention that an asset management system for the transportation sector requires system-level performance measures, models, and interoperable databases used by asset groups to make evidencebased decisions. In the area of passenger urban transport, Hugo et al. [16,17] discuss the relations between some maintenance KPIs, i.e., MTTR, MTBF, and availability, and the dimension of the reserve fleet. According to the Center for Transportation Research and Education (CTRE), transportation agencies could benefit from the adoption of asset management principles. The levels of maturity presented are the following [18]: Organizational goals and objectives; Inventory of pavements, bridges, and other major infrastructure assets; Knowledge of the age, condition, and deterioration of these assets; Availability of information to undertake life cycle cost analysis for all major asset types and asset classes; Information to undertake risk management analysis at the enterprise and program level; Information to develop the organization's financial plan to support investment; Development of investment strategies to manage the network for its whole life. The work of Pais et al. [19] is in line with [9], including a diagnostic model on the state of organizations to help the implementation of ISO 55001. Farinha [20] presents some econometric models to evaluate the LCC, including the withdrawal time for medical equipment. Raposo et al. [21-23] discuss the application of econometric models to LCC in an urban bus fleet based on maintenance costs, as well as their importance in a good management policy. The models include the influence of internal rate of return, as well as the price of fuel to the withdrawal time. Asiedu \& Gu [24] present an interesting product life cycle cost analysis related to Life Cycle Assessment. Nee \& Tan [25] present some methodological approaches. Kloepffer [26] emphasizes a model corresponding to a life cycle sustainability assessment that is the sum of the Life Cycle Assessment, plus the Life Cycle Cost (LCC), plus the Social Life Cycle Assessment (SLCA). Sarma \& Adeli [27] present a paper on the life cycle cost optimization of steel structures, including preventive maintenance, specifically in the systematic painting of steel structure to avoid corrosion. Frangopol \& Liu [28] present a paper on maintenance and the management of civil infrastructure based on condition monitoring, including LCC. Toniolo [29] presents some dimensions of sustainability addressed in international standards using a life cycle perspective. Favi, Campi \& Germani [30] offer a comparative life cycle assessment of metal arc welding technologies using engineering design documentation. They do not evaluate the maintenance area, but they refer to it as an important variable. Moubray [31] says, about reliability centered maintenance, describing the importance of condition monitoring techniques and tools to increase availability and extend an asset's life cycle. In other early work, Rao [32] presents some important condition monitoring techniques and tools, including an analysis of cost-effective benefits. Davies [33] offers a handbook with techniques and tools for condition monitoring. The book emphasizes the economic justification for and benefits of condition monitoring. It also discusses the variable investment in condition monitoring along the asset's life. Nilsson \& Bertling [34] present two case studies of life cycle cost analysis for wind power systems using condition monitoring. The authors demonstrate that using condition monitoring results in improved maintenance planning; investing in these types of maintenance leads to increased availability and increased electricity production. Another consideration is the dispersion of assets, because the investment in logistics may be an important variable of the maintenance budget. In another case of wind farms, Fonseca, Farinha \& Barbosa [35] present a methodology, based on the ant algorithm, demonstrating that in the maintenance management of any asset, not just wind farms, both the policy and the maintenance logistics are key to maximizing the investment in the asset's life cycle. Shina \& Jun H-b [36] propose a general approach to a condition monitoring-based maintenance policy addressing several aspects of condition-based maintenance: definitions, related international standards, 
procedures, and techniques. Wang [37] suggests a prognosis model for wear prediction based on oil monitoring. Oil monitoring is one of the most important techniques to maximize equipment availability, especially combustion engines, rolling bearings, and similar assets. The author reports the development of a wear prediction model based on stochastic filtering and hidden Markov theory. Simões et al. [38] present a state-of-the-art hidden Markov model for predictive maintenance of Diesel engines, demonstrating the importance of investment in a maintenance policy based on oil analysis to maximize buses' availability, maximize the number of passengers transported, and minimize the reserve fleet. Yam et al. [39] propose an intelligent predictive decision support system for Condition-Based Maintenance (CBM). Lebold et al. [40] review the vibration analysis methods for gearbox diagnostics and prognostics. Aherwar \& Khalid [41] review a vibration analysis technique for gearbox diagnosis. Vibration signal analysis is widely used in the detection of faults in rotating machinery. The authors review some current vibration analysis techniques used for condition monitoring of gear faults. Tchomeni \& Alugongo [42] present an experimental diagnosis of multiple faults on a rotor-stator system using fast Fourier transform and wavelet scalogram, researching multiple fault detection for a rotating shaft using a time-frequency method. Electric motors are among the most common and important assets in industry and, indeed, in most economic activities in the world.

\section{Life Cycle Investment - A Holistic Approach}

Farinha [9] presents an integrated vision of physical asset management emphasizing tools to manage the entire life cycle, summarized as comprising the following times and steps:
t1 - Decision for acquisition;
t2 - Terms of reference;
t3 - Market consultation;
t4 - Acquisition;
t5 - Commissioning;
t6 - Starting production / starting maintenance;
t7 - Economic / lifespan;
t8 - Renewal / withdrawal.

The author also shows the relations between the life cycle of physical assets, ISO 5500X standards (55000, 55001, 55002), and some maintenance standards, for example, NP4492 and various associated others [9]. Figure 1 represents Farinha's graphical approach to the life cycle of physical assets including the standards.
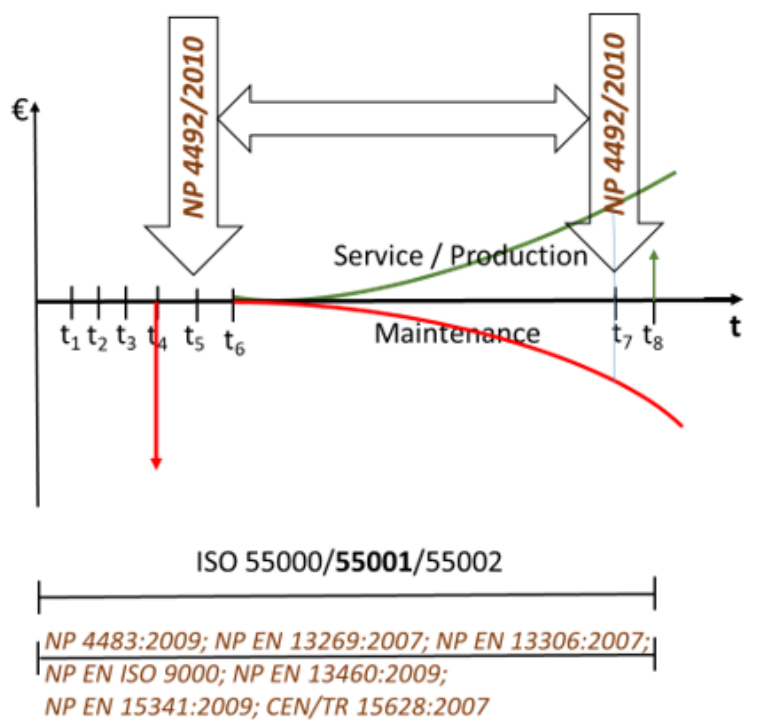

Figure 1: Times of a physical asset life cycle.

As Figure 1 shows, to guarantee the service/production of the physical asset from acquisition to withdrawal, there is a continuous negative financial movement. Interestingly, however, the acquisition financial value is called investment, but the maintenance financial values are called costs! Because of this contradiction, the term Life Cycle Investment (LCI) instead of Life Cycle Cost (LCC), looking specifically at assets used for industrial production purposes. In fact, without ongoing investment along an asset's life cycle to support an adequate maintenance policy, it is not possible to guarantee the availability of the asset to meet its productive function. Therefore, the econometric models used to evaluate the LCI consider all costs and benefits, from initial investment to withdrawal, including all the variables of investments (usually called costs) to guarantee their normal functioning.

\section{Acknowledgement}

None.

\section{Conflict of Interest}

No conflict of interest. 


\section{References}

1. Woodward DG (1997) Life cycle costing - Theory, information acquisition and application. International Journal of Project Management 15(6): 335-344.

2. Goh, BH, Sun Y (2016) The development of life-cycle costing for buildings. Building Research \& Information 44(3): 319-333.

3. Lindholm A, Suomala P (2002) Present and future of life cycle costing: reflections from Finnish companies. Liiketa. Aikakauskirja: Finn J Bus Econ 54: 282-292.

4. Estevan H, Schaefer B (2017) Life Cycle Costing State of the art report ICLEI - Local Governments for Sustainability, European Secretariat. (Ecoinstitut SCCL)

5. Schuh G, Jussen P, Optehostert F (2019) Iterative Cost Assessment of Maintenance Services. 26th CIRP Life Cycle Engineering (LCE) Conference. ScienceDirect. Procedia CIRP 80: 488-493.

6. Kianian B, Kurdve M, Andersson C (2019) Comparing Life Cycle Costing and Performance Part Costing in Assessing Acquisition and Operational Cost of New Manufacturing Technologies. 26 ${ }^{\text {th }}$ CIRP Life Cycle Engineering (LCE) Conference. ScienceDirect. Procedia CIRP 80 428-433. www.elsevier.com/locate/procedia

7. Spickova M, Myskova R (2015) Costs Efficiency Evaluation using Life Cycle Costing as Strategic method. Business Economics and Management 2015 Conference, BEM2015. Procedia Economics and Finance 34: 337 343.

8. Bengtsson M, Kurdve M (2016) Machining Equipment Life Cycle Costing Model with Dynamic Maintenance Cost. 23rd CIRP Conference on Life Cycle Engineering. Procedia CIRP 48: 102-107.

9. Farinha JT (2018) Asset Maintenance Engineering Methodologies. CRC Press; 1st edition (May 29, 2018). English. Printed in USA. ISBN-10: 1138035890. ISBN-13: 978-1138035898.

10. Ljiljana K, Dragutin L, Zelimir D (2014) Asset governance as strategy for physical asset. 7 th International Conference of the School of Economics and Business Conference Proceedings, 13.-14.09.2014., Sarajevo, Bosna i Hercegovina. Pp. 208-221.

11. Stimie JE, Vlok PJ (2016) A Mechanism for the Early Detection and Management of Physical Asset Management Strategy Execution Failure. South African Journal of Industrial Engineering November 2016 Special Edition 27(3): 158-173.

12. Eicher B (2016) Selection of asset investment models by hospitals examination of influencing factors, using Switzerland as an example. International Journal of Health Planning and Management 31: 554-579.

13. Katicic L, Lisjak D, Dulcic Z (2014) Asset governance as strategy for physical asset. 7th International Conference of the School of Economics and Business Conference Proceedings, 13.-14.09.2014., Sarajevo, Bosna i Hercegovina. Pp. 208-221.

14. Banyani MA, Then DSS (2014) A Model for Assessing the Maturity of Facility Management as an Industry Sector. CIB W070 International Conference in Facilities Management. Proceedings of CIB Facilities Management Conference "Using facilities in an Open World - Creating Value for all Stakeholders”. 21-23 May Copenhagen. Pp. 99-110.

15. Volker L, Telli VDL, Ligtvoet A (2011) Developing a maturity model for infrastructural asset management systems. 10th Conference on Applied Infrastructure Research - Infraday 2011

16. Raposo H, Farinha JT, Ferreira, LA, Galar D (2017) Dimensioning Reserve Bus Fleet using Life Cycle Cost Models and Condition Based / Predictive Maintenance - a Case Study. Public Transport. Volume 10 Number 1. Springer Berlin Heidelberg. Pp. 1-22.

17. Raposo H, Farinha JT, Ferreira LA, Galar D (2017) An integrated econometric model for bus replacement and spare reserve based on a condition predictive maintenance model. Maintenance and Reliability. Eksploatacja i Niezawodnosc - Maintenance and Reliability 19(3): 358368.
18. CTRE (2018) Importance of Maturity in Implementing Asset Management. CTRE, Iowa State University center, administered by the Institute for Transportation.

19. Pais E, Raposo H, Meireles A, Farinha JT (2019) ISO 55001 - A Strategic Tool for the Circular Economy - Diagnosis of the Organization's State. Journal of Industrial Engineering and Management Science 1: 89-108.

20. Farinha JMT (2011) Manutenção - A Terologia e as Novas Ferramentas de Gestão. MONITOR, Lisboa, Portugal. ISBN 978-972-9413-82-7.

21. Raposo H, Farinha JT, Fonseca I, Ferreira LA (2019) Condition Monitoring with Prediction Based on Diesel Engine Oil Analysis: A Case Study for Urban Buses. Published by MDPI AG, Basel, Switzerland. Actuators 8(1): 14.

22. Raposo H, Farinha JT, Fonseca I, Galar D (2019) Predicting condition based on oil analysis - A case study. Tribology International. 135: 65-74.

23. Raposo H, Farinha JT, Ferreira LA, Didelet F (2019) Economic life cycle of the bus fleet: a case study. Inderscience Enterprises Ltd. International Journal of Heavy Vehicle Systems (IJHVS) 26(1): 31-54.

24. Asiedu Y, Gu P (1998) Product life cycle cost analysis: State of the art review. International Journal of Production Research 36(4): 883-908.

25. Durairaj SK, Nee AYC, Tan RBH (2002) Evaluation of Life Cycle Cost Analysis Methodologies. Corporate Environmental Strategy. 9(1): 30-39.

26. Kloepffer W (2008) Life Cycle Sustainability Assessment of Products. Int J Life Cycle Assess 13: 89.

27. Sarma KC, Adeli H (2002) Life-cycle cost optimization of steel structures. Int J Numer Meth Eng 55: 1451-1462.

28. Frangopol DM, Liu M (2007) Maintenance and management of civil infrastructure based on condition, safety, optimization, and life-cycle cost. Structure and Infrastructure Engineering 3(1): 29-41.

29. Toniolo S, Mazzi A, Mazzarotto G, Scipioni A (2019) International standards with a life cycle perspective: which dimension of sustainability is addressed? Int J of Life Cycle Assess.

30. Favi C, Campi F, Germani M (2019) Comparative life cycle assessment of metal arc welding technologies by using engineering design documentation. Int J Life Cycle Assess (2019).

31. Moubray J (1997) Reliability-Centered Maintenance Second Edition. Industrial Press, Inc.; Second edition. ISBN-10: 0831131462. ISBN-13: 978-0831131463

32. Rao BKN (1996) Handbook of Condition Monitoring. Elsevier Science. ISBN-10: 1856172341. ISBN-13: 978-1856172349

33. Davies A (1997) Handbook of Condition Monitoring: Techniques and Methodology. Springer. ISBN-10: 0412613204. ISBN-13: 9780412613203

34. Nilsson J, Bertling L (2007) Maintenance Management of Wind Power Systems Using Condition Monitoring Systems - Life Cycle Cost Analysis for Two Case Studies. IEEE Transactions on Energy Conversion 22(1): 223-229.

35. Fonseca I, Farinha JT, Barbosa FM (2014) Maintenance planning in wind farms with allocation of teams using genetic algorithms. IEEE Latin America Transactions 12(6): 1062-1070.

36. Shina JH, Jun Hb (2015) On condition-based maintenance policy. Journal of Computational Design and Engineering.2(2): 119-127.

37. Wang W (2007) A prognosis model for wear prediction based on oilbased monitoring. Journal of the Operational Research Society 58(7): 887-893.

38. Simões A, Viegas J, Farinha JT, Fonseca I (2017) The state of the art of Hidden Markov Models for predictive maintenance of Diesel engines. Quality and Reliability Engineering International. WILEY-BLACKWELL.

39. Yam R, Tse P, Li L, Tu P (2001) Intelligent Predictive Decision Support System for Condition-Based Maintenance. Int J Adv Manuf Technol 17: 383. 
40. Lebold M, McClintic K, Campbell R, Byington C, Maynard K (2000) Review of Vibration Analysis Methods for Gearbox Diagnostics and Prognostics. Proceedings of the $54^{\text {th }}$ Meeting of the Society for Machinery Failure Prevention Technology, Virginia Beach, VA, pp. 623-634.

41. Aherwar A, Khalid MS (2012) Vibration analysis techniques for gearbox diagnostics: a review. International Journal of Advanced Engineering Technology 3(2).
42. Tchomeni BX, Alugongo A (2019) Experimental diagnosis of multiple faults on a rotor-stator system by fast Fourier transform and wavelet scalogram. Vaal University of Technology, Mechanical Engineering Department, Vanderbijlpark, South Africa. 